Canadian

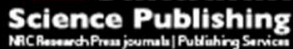

Applied Physiology, Nutrition, and Metabolism Physiologie appliquée, nutrition et métabolisme

\title{
A role for maternally derived myokines to optimize placental function and fetal growth across gestation
}

\begin{tabular}{|r|l|}
\hline Journal: & Applied Physiology, Nutrition, and Metabolism \\
\hline Manuscript ID & apnm-2016-0446.R1 \\
\hline Manuscript Type: & Review \\
\hline Date Submitted by the Author: & O2-Dec-2016 \\
\hline Complete List of Authors: & $\begin{array}{l}\text { Dubé, Chantal; University of Ottawa Faculty of Health Sciences, } \\
\text { Interdisciplinary School of Health Sciences } \\
\text { Aguer, Céline; Institut de Recherche de I'Hôpital Montfort; University of } \\
\text { Ottawa Faculty of Medicine, Biochemistry, Microbiology and Immunology } \\
\text { Adamo, Kristi; University of Ottawa School of Human Kinetics; Children's } \\
\text { Hospital of Eastern Ontario Research Institute, Healthy Active Living and } \\
\text { Obesity Research Group } \\
\text { Bainbridge, Shannon; University of Ottawa Faculty of Health Sciences, } \\
\text { Interdisciplinary School of Health Sciences; University of Ottawa Faculty of } \\
\text { Medicine, Cellular and Molecular Medicine }\end{array}$ \\
\hline Keyword: & $\begin{array}{l}\text { placenta, myokines, physical activity < exercise, pregnancy, skeletal } \\
\text { muscle }\end{array}$ \\
\hline
\end{tabular}


Title: A role for maternally derived myokines to optimize placental function and fetal growth across gestation

Authors (co-corresponding authors underlined): Chantal Dubéa (e-mail:

Cdube006@uottawa.ca), Céline Aguer ${ }^{\text {b,c }}$ (e-mail: Celineaguer@montfort.on.ca), $\underline{\text { Kristi Adamo }}^{\text {d,e }}$ (e-mail: Kristi.Adamo@uottawa.ca) \& $\underline{\text { Shannon Bainbridge }}{ }^{\text {a,f }}$ (e-mail:

\section{Shannon.bainbridge@uottawa.ca)}

${ }^{\text {a }}$ Interdisciplinary School of Health Sciences, University of Ottawa, Ottawa, Canada K1N 6N5

${ }^{\mathrm{b}}$ Institut de recherche de I’Hôpital Montfort, Ottawa, Canada K1K OT1

${ }^{\mathrm{c}}$ Biochemistry, Microbiology and Immunology department, Faculty of Medicine, University of Ottawa, Canada K1H 8M5

${ }^{\mathrm{d}}$ School of Human Kinetics, University of Ottawa, Ottawa, Canada K1N 1A2

${ }^{\mathrm{e}}$ Healthy Active Living and Obesity Research Group, Children's Hospital of Eastern Ontario Research Institute, Ottawa, Canada, K1H 8L1

${ }^{\mathrm{f}}$ Department of Cellular and Molecular Medicine, University of Ottawa, Ottawa, Canada K1H $8 \mathrm{M} 5$

Co-Corresponding authors addresses: Kristi Adamo, School of Human Kinetics, Faculty of Health Sciences, Rm E250F, 200 Lees, University of Ottawa, Ottawa, Canada, K1S 5S9; Tel.: 1613-562-5800 ext. 1009; E-mail: kristi.adamo@uottawa.ca. Shannon Bainbridge, Faculty of Health Sciences, Rm 3028, Roger Guindon Hall, 451 Smyth Rd, University of Ottawa, Ottawa, Canada K1H 8M5; Tel.: 1-613-562-5800 ext. 8569; E-mail: shannon.bainbridge@uottawa.ca. 
A role for maternally derived myokines to optimize placental function and fetal growth across gestation

\begin{abstract}
Exercise during pregnancy is associated with improved health outcomes for both mother and baby, including a reduced risk of future obesity and susceptibility to chronic diseases. Overwhelming evidence demonstrates a protective effect of maternal exercise against fetal birth weight extremes, reducing the rates of both large- and small-for-gestational-age infants. It is speculated that this protective effect is mediated in part through exercise-induced regulation of maternal physiology and placental development/function. However, the specific mechanisms through which maternal exercise regulates these changes remain to be discovered. We hypothesize that myokines, a collection of peptides and cytokines secreted from contracting skeletal muscles during exercise, may be an important missing link in the story. Myokines are known to reduce inflammation, improve metabolism and enhance macronutrient transporter expression/activity in various tissues of non-pregnant individuals. Little research to date has focused on the specific roles of the myokine secretome in the context of pregnancy; however, it is likely that myokines secreted from exercising skeletal muscles may modulate the maternal milieu and directly impact the vital organ of pregnancy - the placenta. In the current review, data in strong support of this potential role of myokines will be presented, suggesting myokine secretion as a key mechanism through which maternal exercise optimizes fetal growth trajectories. It is clear that further research is warranted in this area, as knowledge of the biological roles of myokines in the context of pregnancy would better inform clinical recommendations for exercise during pregnancy and contribute to the development of important therapeutic interventions.
\end{abstract}


Key Words: Placenta, myokines, physical activity, exercise, pregnancy, skeletal muscle, physiology, development, transport, fetal growth. 
Gestation is the period between conception and birth, during which a one-cell zygote divides and develops into a fetus with fully-formed and functional organ systems. This rapid period of fetal growth is accommodated by considerable adaptations to maternal physiology, including a 40-50\% increase in maternal blood volume, increased cardiac output, systemic vasodilation, and maternal hyperinsulinemia to maintain normal glucose homeostasis (Hytten and Paintin 1963, Sibai and Frangieh 1995, Baz et al. 2016). These maternal adaptations serve to increase placental blood flow, and maternal-fetal nutrient and gas exchange. Regular physical activity during this period can further modify maternal physiology, and is associated with reductions in obstetrical complications, optimized fetal growth trajectories and improved long-term health outcomes for mothers and their offspring (Ferraro et al. 2012).

The placenta is the vital organ of pregnancy, across which all maternal-fetal exchange takes place, and as such plays a critical role in dictating fetal growth. Processes of early placentation, including uterine invasion by the placental trophoblast cells and establishment of a robust utero-placental circulation, are critical to ensuring optimized nutrient and gas delivery to the developing fetus. Across gestation the materno-fetal exchange surface area within the placenta expands from $\sim 1.5 \mathrm{~m}^{2}$ in the first trimester up to $14 \mathrm{~m}^{2}$ in the third trimester (Jackson et al. 1992), as the placental villous trees encasing the feto-placental vasculature continue to branch and mature. Specific transporters for all major classes of macronutrients (i.e. glucose, lipids, and amino acids (AAs)) - the building blocks for fetal growth - are present in abundance along the surface of the placental villous trees, and their expression/activity are directly associated with increased fetal growth (Jansson and Powell 2000). It has been postulated that physical activity during pregnancy not only improves maternal physiology to enhance utero- 
placental perfusion, but may play a more direct role in optimizing fetal growth by regulating critical processes involved in placental development/function. However, the specific mechanisms through which maternal exercise can directly modulate these processes within the placenta remain to be discovered.

In the current review, the potential role of maternally-derived myokines as important regulators of placental development/function will be presented. Myokines, a collection of peptides and cytokines secreted from contracting skeletal muscles during exercise, which will henceforth be referred to as the 'myokine secretome', have beneficial effects on metabolism and macronutrient transport in non-pregnant tissues, including the brain, liver, pancreas, skeletal muscle and adipose tissue (Ellingsgaard et al. 2011, Pedersen 2011). While similar effects are likely present in the context of pregnancy, the exercising myokine secretome has not been adequately assessed in pregnant women nor have the effects of this secretome on placental function and/or fetal growth been fully investigated. We hypothesize that myokines may be important signalling molecules acting at the level of the placenta linking maternal exercise to optimized fetal growth trajectories.

\section{Exercise during Pregnancy}

Exercise is an important part of a healthy pregnancy. Studies have consistently demonstrated that regardless of pre-pregnancy activity levels, women with uncomplicated singleton pregnancies are at a low risk of adverse maternal and fetal exercise-related events (i.e. gestational hypertension and preterm birth) (Bredin et al. 2013, Cid and González 2016). With these findings, the previous contention that pregnancy is a medical condition requiring a sedentary lifestyle has been strongly disproven (Dempsey et al. 2005). Published literature now 
demonstrates numerous positive health benefits associated with maternal exercise, as detailed below, and has led to the encouragement of physical activity throughout gestation. Despite this evidence, most pregnant women still fail to meet the recommended levels of physical activity during pregnancy (Borodulin et al. 2008). Among the many self-reported reasons for the lack of adherence to exercise guidelines (i.e. nausea and fatigue), safety concerns of participating in physical activity during pregnancy predominate in women and these concerns have been found to predict the amount and/or intensity of exercise that they participate in throughout their pregnancy (Duncombe et al. 2009). As such, an increased focus must be placed on highlighting the overwhelming evidence of the health benefits of exercise during pregnancy to reassure mothers that the many benefits largely outweigh the risks.

In 2002, the Canadian Society for Exercise Physiology (CSEP) developed the Physical Activity Readiness Medical Examination for Pregnancy (PARmed-X), a screening tool for health care providers to use to clear women to safely participate in exercise during pregnancy (Wolfe and Mottola 2002). In 2003, the Society of Obstetricians and Gynecologists of Canada (SOGC) and the American Congress of Obstetrics and Gynecology (ACOG) developed recommendations for exercise during pregnancy and the post-partum period, recommending 30 minutes of aerobic exercise 4 times per week in uncomplicated pregnancies (i.e. in the absence of absolute contraindications like preeclampsia) (Artal et al. 2003, Davies et al. 2003). Currently, the ACOG guidelines recommend that women participate in physical activity on most, if not all days of the week (The ACOG 2015). At present, an expert panel is working on updating the Canadian guidelines as well. 
The benefits of exercise during pregnancy are extensive for the mother and her offspring, extending into the long term for both. Strong epidemiological evidence indicates that regular exercise during pregnancy prevents excessive maternal gestational weight gain (GWG) and thus minimizes postpartum weight retention and the risk of developing health problems like diabetes, metabolic syndrome and cardiovascular disease (CVD) (Walker 2007, Ferraro et al. 2012, Nascimento et al. 2014). As reviewed, maternal exercise also minimizes the risk of developing pregnancy-specific conditions including gestational diabetes mellitus (GDM) and preeclampsia - a hypertensive disorder of pregnancy (Ferraro et al. 2012). The maternal health benefits achieved from engaging in exercise highlight the importance of promoting an active lifestyle before, during and after pregnancy for all women. Further, the offspring of exercising mothers overwhelmingly benefit from the effects of physical activity during pregnancy. The offspring demonstrate optimized birth weights and body composition - with reduced birth weight extremes and reduced fat mass at birth (within the healthy range) - and they maintain this morphometric profile into early childhood, with reduced rates of later childhood obesity (Clapp 1996). Evidence suggests that exercise later in pregnancy prevents excess fetal growth as women who maintain regular exercise during the second and third trimesters of pregnancy have a reduced risk of delivering an LGA infant (Owe et al. 2009, Juhl et al. 2010, Hopkins and Cutfield 2011). Importantly, this decreased risk of LGA is not accompanied by an increased risk of delivering an SGA infant (Hopkins and Cutfield 2011), but instead with a reduced risk of SGA (Juhl et al. 2010). Thus, exercise reduces the risk of birthweight extremes while promoting appropriate-for-gestational-age offspring. This is important as children born at both birthweight extremes are at an increased risk of later obesity and subsequent comorbidities (i.e. diabetes 
and CVD) (Pettitt and Jovanovic 2001, Oken and Gillman 2003, Whitaker 2004). The specific mechanisms underpinning the regulation of fetal growth by maternal exercise are still unclear but are likely the combined result of improved maternal physiology and optimized development/function of the placenta.

\section{Potential Mechanisms of Optimized Fetal Growth Mediated by Maternal Exercise}

\section{Exercise-induced Adaptations to Maternal Physiology}

Exercise during pregnancy results in several adaptations to maternal physiology. These changes are designed to protect the developing fetus and to ensure that both the needs of the mother and the fetus are met. For example, exercise during pregnancy is associated with changes in maternal blood glucose levels (Clapp and Capeless 1991, Clapp et al. 1995). In response to a bout of maternal exercise after 23 weeks of gestation, the increase in skeletal muscle glucose oxidation and decrease in hepatic glucose production results in a transient reduction in blood glucose levels (not associated with exercise intensity), likely due to increasing feto-placental demands as pregnancy progresses (Clapp and Capeless 1991).This reduction in blood glucose levels in pregnancy differs from the typical transient hyperglycemic response observed in non-pregnant individuals upon engaging in physical activity (Zinker et al. 1990). As reviewed by Ferraro and colleagues (2012), aerobic exercise has further been associated with improved insulin sensitivity in pregnant women, enhancing overall glycemic control and reducing the risk of developing GDM. Energy expenditure during exercise also increases during pregnancy. Total energy expenditure is represented by oxygen uptake $\left(\mathrm{VO}_{2}\right)$, the sum of the calories used at rest and during participation in physical activities. Total energy expenditure increases by up to $19 \%$ in the third trimester of pregnancy (compared to non- 
pregnant individuals) due to GWG (Butte et al. 2004). As such, as pregnancy progresses the metabolic demands of exercise increase in proportion to the total amount of weight gained (O'Toole 2003). The maternal increase in oxygen consumption during pregnancy is essential to meet the energy demands associated with increased maternal body weight and increased work of breathing, and to ensure that the fetus has a constant supply of energy for growth and development (O’Toole 2003). Further, maternal cardiovascular adaptations occur during pregnancy to ensure adequate delivery of oxygen and nutrient-filled blood to the developing fetus. As reviewed by Barakat et al. (2015), these adaptations consist of overall increases in maternal blood volume, heart rate, stroke volume and cardiac output to enhance uteroplacental perfusion, promoting fetal growth. During exercise, the chest wall of pregnant women also changes (i.e. increased elasticity and expansion) to enhance the capacity for ventilation as the fetus increasingly places pressure on the maternal diaphragm resulting in laboured breathing (Soultanakis et al. 1996). Although blood flow to skeletal muscle is enhanced during exercise, adequate delivery of oxygen and nutrients to the fetus is maintained, with no harms to the fetus (Clapp et al. 1995, Artal and Sherman 1999, Artal et al. 2003). These changes in maternal biology in response to exercise ultimately optimize fetal growth by providing the developing offspring with the appropriate substrates for growth.

\section{Exercise-induced Alterations in Placental Development}

In addition to adaptations to maternal physiology, exercise during pregnancy can improve critical processes involved in placental development. Total placental volume, via ultrasound and gross measurements, is increased across gestation in exercising women. The rise in mid-pregnancy placental growth rates is estimated to be $\sim 24 \%$ higher in exercising 
compared to sedentary pregnant women (Clapp et al. 2000a, Clapp 2003). Importantly, these changes in overall placental volume have been histologically attributed to changes in 'functional' placental volume, with the largest increases seen in the terminal components of the placental villous trees (Clapp et al. 2000a). These terminal villi are active in maternal-fetal exchange as opposed to villi in the stem or intermediate components of the villous trees, which act as conduits for the larger fetal umbilical vessels (Clapp et al. 2000a). Detailed histomorphometric investigations of placental biopsies also demonstrate greater total vascular volume and total capillary volume in the placental villous trees of women regularly engaging in exercise (Jackson et al. 1995), coupled with an increased presence of proliferating trophoblast and endothelial cells (Bergmann et al. 2004). Taken together these findings are indicative of a pro-angiogenic effect of maternal exercise on the developing placenta. Based on previous findings regarding the effects of exercise on angiogenesis and placental perfusion (Feldser et al. 1999, Clapp et al. 2000b, Zygmunt et al. 2002, Herr et al. 2003), it has been speculated that this effect may be an adaptive response of the placenta to reduced tissue oxygenation and/or glucose availability during bouts of vigorous exercise, resulting in activation of hypoxiainducible transcription factors and stimulation of the VEGF-IGF II pro-angiogenic pathways. However, the $10-50 \%$ baseline augmentation in pregnancy-associated increases in plasma volume, placental intervillous space blood volume, placental volume and cardiac output observed in pregnant women who regularly participate in sustained weight-bearing exercise during pregnancy helps to buffer some of the acute reductions in placental and fetal oxygen content measured following bouts of acute maternal exercise typically observed in sedentary women (Clapp 2003). As reported by Davenport et al. (2016), current evidence suggests that 
blood flow delivery to the fetus is maintained during exercise, although the mechanisms underlying the protection of blood flow to the fetal unit are largely unknown. Current studies have found that the fetal heart adapts to exercise training, resulting in fetal cardiovascular adaptations to maternal exercise, including fetal heart rate modulation and improved autonomic control (May et al. 2010, Moyer et al. 2015). Studies have identified positive correlations between fetal heart adaptability and heart rate variability in response to maternal aerobic and resistance exercise training during pregnancy, with more fetal cardiovascular adaptations occurring in response to exercise of higher intensity and of longer duration (May et al. 2012). The occurrence of exercise-related events concerning fetal heart rate such as bradycardia (the slowing of fetal heart rate), a protective mechanism in response to maternal hypoxia, has been found to be low in relation to the number of exercise hours and in all instances, appears to be transient, with fetal heart rate always returning to normal in the postexercise period (Charlesworth et al. 2011).

Collectively, adaptations to placental structure observed in regularly active women are likely driven by additional exercise-induced mechanisms which warrant further investigation. What is clear, however, is that maternal exercise is capable of modulating placental development in such a way as to enhance the capacity for maternal-fetal exchange. It is therefore no surprise that these exercise-induced increases in functional placental volume and vascular development ensure adequate nutrient and oxygen delivery to the fetus to support optimal fetal growth trajectories (Clapp et al. 2000a). The proper early development and structure of the placenta is certainly paramount to successful fetal growth, but ultimately the optimized functioning of this organ across pregnancy will dictate fetal growth trajectories. 


\section{Exercise-induced Alterations in Placental Macronutrient Transport}

There is a growing body of evidence suggesting a protective role of maternal exercise on several critical functions of the placenta across gestation which could serve to optimize fetal growth. With proper nutrition, the fetus is provided with adequate nutrient supply during bouts of maternal physical activity (Bessinger and McMurray 2003, Gavard and Artal 2008). The exact mechanisms by which maternal exercise mediates changes in substrate delivery across the placenta via alterations in the expression and/or activity of placental macronutrient transporters are currently unclear. However, there is mounting evidence to support an 'exercise-sensing role' for the mammalian target of rapamycin (mTOR) pathway, which is known to integrate maternal, fetal, and placental signals (i.e. growth factors, stress, energy status, oxygen and AA) to regulate macronutrient transporter expression/activity (Roos et al. 2007, 2009, Laplante and Sabatini 2012). Jansson and Powell (2013) have suggested a "placenta nutrient sensing model" suggesting that mTOR integrates these signals from the mother and fetus to regulate fetal growth (Roos et al. 2009, Laplante and Sabatini 2012). Inhibition of the mTOR signaling pathway significantly reduces the activity of placental AA transporters (Roos et al. 2007, 2009). In the placentas of active pregnant women, the expression of members of the placental mTOR signaling pathway (i.e. positive regulators IGF1 and IRS1; negative regulators PRKAB1 and TSC2) are lowered (Brett et al. 2015). In fact, moderate-to-vigorous physical activity (MVPA) in pregnant women is inversely correlated with the expression of mTOR and IGF-1, a peptide that plays an important role in fetal growth (Chiesa et al. 2008). Reduced expression of positive or negative regulators of mTOR, if accompanied by reduced protein levels, could result in either a reduction or increase in placental mTOR signaling, respectively 
(Brett et al. 2015). Because no differences in birthweights were observed between the offspring of active and inactive pregnant women, physical activity during pregnancy appears to optimize mTOR signaling and nutrient delivery to the fetus in order to optimize neonatal body composition and normalize fetal growth, protecting against fetal birth weight extremes (Brett et al. 2015). Thus, in response to exercise during pregnancy, mTOR is either upregulated in response to excess maternal nutrient availability to limit excess nutrient delivery to the fetus, or downregulated when nutrient availability is limited, suggesting that the placenta matches fetal growth with the availability of maternal nutrients. The mechanisms through which the placenta may in fact 'sense' exercise during pregnancy to modulate the mTOR signaling pathway and subsequent placental functions is an area ripe for further investigation.

Exercise can both positively and negatively alter gene expression and/or activity of many macronutrient transporters within the placenta, including transporters for lipids, AAs and glucose. Pregnant women who meet exercise guidelines during the second trimester of pregnancy demonstrate a nearly 2-fold lowered mRNA expression of the free fatty acid (FA) transporter protein 4 (FATP4) compared to sedentary women (Brett et al. 2015), with no measurable changes in expression of any of the other FA transporters. This is particularly intriguing as FATP4 is considered the primary placental transporter for long-chained polyunsaturated FAs (Larqué et al. 2006), the FAs responsible for the rapid fetal fat accumulation in the third trimester (Haggarty 2010). Thus, lower FATP4 expression suggests a reduced potential for the transport of FAs to the fetus, a notion that is supported by the reduced neonatal fat mass observed in the offspring of exercising pregnant women (Clapp and Capeless 1990, Harrod et al. 2014). Placentas from these same physically active women also 
demonstrate an increase in mRNA expression of a key sodium-dependent neutral AA transporter, System A (SNAT2) (Brett et al. 2015). Placental SNAT2 expression is intimately linked to fetal growth profiles (Jansson and Powell 2006), with strong associations noted between insufficient placental SNAT2 expression and intrauterine fetal growth restriction (IUGR) (Mandò et al. 2013). It is postulated that the reduced potential for FA transport and increased potential for AA transport to the fetus in active pregnant women does not alter fetal birth weights, but rather improves neonatal body composition by increasing lean muscle mass and decreasing fat mass (Brett et al. 2015). Furthermore, when controlling for total sugar intake, MVPA has been inversely correlated with placental GLUT1 expression (Brett et al. 2015). This finding suggests a reduced potential for glucose transport to the fetus in active pregnant women. However, the strong positive correlation between maternal carbohydrate intake and the expression of GLUT1 also suggests increased potential for glucose transport to the fetus and provides evidence that the placenta acts as a nutrient sensor, altering glucose transport to match maternal carbohydrate availability (Jansson and Powell 2006, Brett et al. 2015). As demonstrated through these three examples, the effects of maternal exercise on macronutrient transporter expression and/or activity appear to be transporter specific, with further evidence of differential responses to the maternal exercise in question (Brett et al. 2015). This complex regulatory dynamic may help explain the ability of maternal exercise to prevent fetal birth weight extremes. An important question still remains however; how does maternal physical exercise - the process of repeat muscle contractions in the mother - directly signal to the fetoplacental unit and result in optimized placental development and function? Myokines secreted from contracting skeletal muscle, may be a missing piece to this puzzle. 


\section{Myokines}

During physical activity, skeletal muscle contractions stimulate the production and secretion of hundreds of peptides and cytokines - collectively known as myokines. Myokines participate in autocrine, paracrine and endocrine signalling throughout the body (Pedersen et al. 2007). These exercise factors are known to mediate some of the beneficial health effects of exercise and protect against chronic diseases associated with low-grade inflammation and impaired metabolism (i.e. diabetes and CVD) (Petersen and Pedersen 2005). In non-pregnant individuals, myokines have been found to regulate cellular metabolism and macronutrient transport (i.e. promote lipid metabolism and glucose uptake in skeletal muscle and adipose tissue). In the context of pregnancy, there is a lack of work examining the effects of myokines, as a collective secretome, on maternal physiology and placental development/function. However, several individual cytokines, chemokines and peptides identified within the myokine secretome have been found to alter placental development/function, including the expression/activity of placental macronutrient transport proteins. As such, we speculate that myokines may act as important signalling molecules between maternal skeletal muscle and the placenta, regulating maternal-fetal nutrient exchange and fetal growth. Although the exact mechanisms underlying the regulation of fetal growth In response to maternal exercise are still unclear, myokines may be one of the exercise-induced factors involved in promoting normal fetal growth trajectories, as they appear to have a potential role for improving maternal physiology and optimizing the development/function of the placenta. Evidence in support of this hypothesis for a few key constituents of the myokine secretome is presented below.

\section{Interleukin-6}


As the first myokine discovered (Pedersen and Febbraio 2008), the biological role of interleukin-6 (IL-6) has been extensively studied in the context of exercise physiology. Dependent on the environment, IL-6 can act as an inflammatory cytokine produced by macrophages or as an anti-inflammatory myokine produced by exercising skeletal muscle (Pedersen and Febbraio 2008). IL-6 mRNA and protein expression as well as levels in circulation are highly elevated in response to acute exercise, increasing exponentially until reaching maximal plasma levels at the end of an exercise session (up to 100-fold) (Pedersen and Fischer 2007), and rapidly declining to basal levels in the post-exercise period (Pedersen and HoffmanGoetz 2000, Suzuki et al. 2002, Febbraio and Pedersen 2002). Several studies have provided evidence in support of the notion that skeletal muscle is responsible for the systemic increase in IL-6 in response to exercise. As reviewed by Pedersen and Febbraio (2012), this evidence is based on transcriptional analysis of IL-6, in situ hybridization and immunohistochemistry of skeletal muscle biopsies, and microdialysis of exercising skeletal muscle. Further, arterialfemoral differences in IL-6 concentration across an exercising leg has shown that it is released in large amounts into circulation, accounting for the exercise-induced systemic increase in IL- 6 (Steensberg et al. 2000). In contrast, chronic exercise training has been shown to decrease basal IL-6 levels and diminish the typical increase in IL-6 mRNA and plasma levels in response to endurance exercise in untrained men (Fischer et al. 2004). Endurance exercise has also been associated with enhanced gene and protein expression of the IL- 6 receptor (IL-6R) $\alpha$, increasing the number of receptors and overall sensitivity to IL-6 (Keller et al. 2005).

IL-6 is believed to deliver the health benefits of regular exercise through its antiinflammatory effects and ability to regulate lipid and glucose metabolism. IL-6 is thought to 
mediate the anti-inflammatory effects of exercise, in part through stimulating the release of anti-inflammatory cytokines IL-10 and IL-1 receptor antagonist (IL-1RA) into circulation (Steensberg et al. 2003) and by inhibiting the production of TNF- $\alpha$ (Starkie et al. 2003). IL-6 is also thought to provide protection from TNF-induced insulin resistance (Petersen and Pedersen 2005). In skeletal muscle and adipose tissue, IL-6 stimulates glucose uptake and fat oxidation, partially via the activation of AMP-activated protein kinase (AMPK) (Kelly et al. 2004). IL-6 also increases whole-body lipolysis, fat oxidation and FA re-esterifiction in the absence of hypertriglyceridemia (van Hall et al. 2003). Further, IL-6 exerts endocrine effects on the liver to induce hepatic glucose production (Febbraio et al. 2004, Pedersen 2009). These exerciseinduced effects of IL-6 on glucose and fat metabolism, and in reducing inflammation observed in non-pregnant individuals are likely to be mirrored in the pregnant population. The actions of IL-6 would provide an improved maternal milieu via enhanced glycemic control, use of nutrients and reduced inflammation to better support optimal fetal growth.

IL-6 has been shown to have important effects on glucose, AA and FA transport in cultured skeletal muscle and in human placental trophoblast cells. In rat myotubes, IL-6 enhances glucose transport and translocation of GLUT-4 to the muscle plasma membrane, as well as insulin-stimulated glucose uptake (Carey et al. 2006). In another in vitro study, effects on glucose uptake via GLUT-4 were only observed at post-exercise cytokine levels when IL-6 was combined with either IL-8 or IL-15, combinations likely present in circulation post-exercise (Gray and Kamolrat 2011). GLUT-4 is also expressed in first trimester human placenta and appears to have a role in glucose uptake early on in pregnancy (as reviewed by Brett et al. 2014). Thus, IL-6 secretion in response to exercise early on in pregnancy may have an impact on 
placental glucose uptake via GLUT-4 and the subsequent transfer of glucose to the fetus, although this remains to be investigated. IL-6 has been shown to directly modulate placental FA transporters. In vitro studies have found that IL-6 stimulates FA accumulation by cultured primary human placental trophoblast cells via an unknown mechanism (Lager et al. 2011). FA accumulation by trophoblast cells in response to IL-6 could contribute to the adequate transfer of nutrients to the fetus during pregnancy (Lager et al. 2011). Interestingly, FATP4 mRNA expression is downregulated by long-term exposure to IL-6 (Lager et al. 2011), similar to the changes in FATP4 mRNA observed in the placentas of exercising women (Brett et al. 2015). With respect to AA transport, IL-6 at physiological concentrations has been found to increase the expression of SNAT2 in cultured human primary placental trophoblast cells, resulting in increased activity of system A (Jones et al. 2009). Interestingly, a similar 2-fold increase in SNAT2 expression is observed in the placentas of women adhering to the guidelines for exercise during pregnancy (Brett et al. 2015). This along with the known role of SNAT2 suggests that women who exercise during pregnancy may have increased potential for AA transport to the fetus via SNAT2 in order to meet the nutrient needs of the fetus and achieve optimal fetal body composition (Brett et al. 2015). It has previously been demonstrated that the activity of the insulin/IGF-1 and mTOR signaling pathways, system A activity, and protein expression of SNAT2 are increased in the placentas of obese women with LGA babies due to the overstimulation of AA transporters and excessive transfer of nutrients to the fetus (Jansson et al. 2013). In obese pregnant women, SNAT2 expression has also been positively correlated to maternal prepregnancy BMI and birth weight, suggesting a mechanism linking maternal obesity to fetal overgrowth (Jansson et al. 2013). Thus, the decreased expression and activity of SNAT4 in 
obese compared to lean pregnant women (with no corresponding changes in infant birthweight) and unchanged expression of SNAT1 and SNAT2, suggests that obese pregnant women may have decreased transfer of amino acids and increased transport of FFA and/or glucose across the placenta. We hypothesize that this could result in offspring of similar weight in obese and lean women, with increased adiposity and lower lean mass in the offspring of obese mothers. Despite the contradictory results from the literature, which is likely the result of inadequately addressing other important contributors to energy balance (i.e. exercise and nutrition), some evidence suggests a possible link between maternal obesity, altered amino acid transport and increased fetal growth. We propose that in response to exercise during pregnancy, the differential expression of macronutrient transporters in concert provides a specific compliment of nutrients to the fetus so that overall caloric exposure to the fetus and infant birthweight is maintained, but offspring body composition is largely improved (greater lean mass and decreased fat mass). We hypothesize that exercise-induced IL-6 myokine secretion (anti-inflammatory), shown to suppress TNF- $\alpha$, could be regulating fetal growth by preventing the over-stimulation of these $A A$ transporters and excessive $A A$ uptake. In the context of pregnancy, increased maternal IL-6 levels in response to exercise may enhance glucose and AA transport and attenuate FA transport, in order to promote appropriate fetal growth trajectories and neonatal body composition (increased lean mass and decreased fat mass).

\section{$\underline{\text { Interleukin-15 }}$}

IL-15 is produced by skeletal muscle in response to exercise-induced contractions. Current published data are conflicting as to how IL-15 expression, protein level and secretion 
from skeletal muscle are influenced by exercise type, duration and intensity as well as the importance of individual activity level and health status (Görgens et al. 2015). Muscular IL-15 mRNA levels are upregulated 2-fold in skeletal muscle in response to a bout of resistance exercise whereas endurance exercise has been found to increase basal skeletal muscle IL-15 protein content by $40 \%$ (Nielsen et al. 2007, Rinnov et al. 2014). In these studies, neither resistance nor endurance exercise increased circulating plasma IL-15 (Nielsen et al. 2007, Rinnov et al. 2014). However, the subjects in these studies were previously active and it is possible that their basal IL-15 levels were already elevated. Other studies have found that acute endurance exercise increases systemic IL-15 levels (Riechman et al. 2004, Tamura et al. 2011), with the most significant effects resulting from acute, moderate intensity resistance exercise (Yeo et al. 2012). In both active and inactive individuals, no changes in resting circulating levels of IL-15 have been observed following any chronic exercise programs (Nieman et al. 2003, Riechman et al. 2004, Rinnov et al. 2014). Furthermore, although IL-15 is up-regulated in skeletal muscle in response to exercise, studies have yet to show that this directly contributes to the systemic increase in IL-15 concentration (Raschke and Eckel 2013). More work remains to be done to elucidate the effects of exercise on IL-15 expression, protein level and secretion from skeletal muscle in humans.

IL-15 on its own is thought to play a role in modulating skeletal muscle and adipose tissue mass as well as in enhancing glucose metabolism and insulin sensitivity. It has been described as an endocrine modulator of visceral fat mass (Pedersen 2009) and likely has a role in modulating fat-to-lean body composition and insulin sensitivity (Pedersen et al. 2007). A study with transgenic mice exhibiting muscle-specific oversecretion of IL-15 found that IL-15 
protects against diet-induced obesity, improves insulin sensitivity, and increases oxidative muscle metabolism (Quinn et al. 2011). IL-15 secreted in response to exercise during pregnancy may enhance the maternal milieu by regulating maternal body composition, increasing insulin sensitivity, and improving skeletal muscle oxygen metabolism.

The exact impact of IL-15 on placental development and function is unknown. However, IL-15 appears to have a beneficial effect on the process of uterine invasion and spiral artery remodeling by placental trophoblast cells, a critical process in the establishment of a robust utero-placental circulation. In vitro, IL-15 has been found to directly increase human placental trophoblast cell migration and invasion in a dose-dependent manner (Zygmunt et al. 1998). This work has been complemented with work in an IL-15 knock-out murine model, in which IL-15 was shown to be essential for the recruitment of uterine natural killer cell to the uterine wall, a process required for the appropriate priming of uterine blood vessels for remodeling by the invading trophoblast cells (Barber and Pollard 2003). Pregnant IL-15 knock-out mice gave rise to growth restricted fetuses, secondary to insufficient remodelling of the uterine spiral arteries and reduced placental perfusion (Barber and Pollard 2003). Extrapolating these findings to the potential roles of exercise-secreted IL-15 in active pregnant women, we could speculate that IL15 in the myokine secretome may enhance natural killer cell recruitment to the maternal decidua and increase early uterine trophoblast invasion, collectively augmenting the capacity of the utero-placental circulation and improving placental perfusion across gestation.

Similar to IL-6, IL-15 appears to have a role in skeletal muscle glucose metabolism and has been associated with increases in GLUT-4 mRNA expression and glucose uptake in C2C12 mouse myoblasts (Busquets et al. 2006, Gray and Kamolrat 2011). However, the effects on 
glucose uptake via GLUT-4 were only observed at post-exercise cytokine levels when combined with IL-6, a combination likely to exist in circulation post-exercise (Gray and Kamolrat 2011). Placental GLUT-4 has a role in glucose uptake early on in pregnancy, with GLUT-1 playing a greater role later in gestation. Thus, acute exercise-induced increases in IL-15 in the first trimester may have an impact on placental glucose uptake via GLUT-4 and the transfer of glucose to the developing fetus, although this warrants further investigation. IL-15 is a promising candidate for beneficial effects on placental development/function in response to its exercise-induced release during pregnancy.

\section{Fractalkine/CX3CL1}

Fractalkine (FKN/CX3CL1) is a newly described myokine whose expression and systemic concentration are elevated in humans in response to acute endurance exercise (Catoire et al. 2014). FKN/CX3CL1 is known to exert its effects locally to promote skeletal muscle regeneration, but it is unclear if the increase in circulating FKN/CX3CL1 levels post-exercise results in other systemic effects (Catoire and Kersten 2015). One potential systemic effect of relevance may be the ability of FKN/CX3CL1 to stimulate cellular glucose uptake, as previously reported in pancreatic cancer cells (Ren et al. 2013). Deficiencies in FKN/CX3CL1 signalling have further been implicated in pancreatic islet $\beta$-cell dysfunction, insufficient insulin secretion and decreased glucose uptake in cases of type 2 diabetes (Lee et al. 2013). While these findings have been reported outside the context of FKN/CX3CL1 as a myokine, they certainly provide an indication as to its potential role and securing its candidacy as a systemic regulator of glucose metabolism and insulin sensitivity in active individuals. This is particularly intriguing in the 
current discussion, considering the significance of appropriate maternal glycemic control during pregnancy to ensure optimal fetal growth.

Studied in isolation, FKN/CX3CL1 has emerged as a potent regulator of early placental development. Investigation of early implantation sites demonstrates abundant expression of FKN/CX3CL1 within the uterine decidual tissues and concurrent expression of the receptor for FKN/CXC3L1 on the surface of invading placental trophoblast cells, particularly those trophoblast cells responsible for remodelling the uterine spiral arteries into high conductance vessels (Hannan et al. 2006). In vitro data has demonstrated an increase in trophoblast adhesion molecules, an increase in secretion of extracellular matrix proteases and a dosedependent increase in trophoblast migration following FKN/CX3CL1 exposure (Hannan et al. 2006, Hannan and Salamonsen 2008). Taken together, these data indicate an important role for this chemokine in the early invasion of the uterine wall by trophoblast cells and establishment of the utero-placental circulation. FKN/CXC3L1 and its receptor are also found in abundance within feto-placental vascular endothelial cells (Szukiewicz et al. 2013). Given the known roles of FKN/CXC3L1 in the promotion of endothelial cell proliferation and capillary tube formation in vitro (Ryu et al. 2008), and the more recent findings of FKN/CXC3L1-mediated placental microvasculature remodeling in diabetic pregnancies (Szukiewicz et al. 2013), an important role for FKN/CXC3L1 in the development of the feto-placental vasculature has additionally emerged. To date, no functional studies have been performed on placental tissues in response to FKN/CXC3L1. However, we would speculate that increases in systemic FKN/CX3CL1 levels from maternal exercise in pregnancy may serve to further promote placental development to 
optimize gas and nutrient supply to the developing fetus and thus aid in the optimization of fetal growth trajectories in exercising women.

$\underline{\text { Irisin }}$

Irisin is a highly controversial myokine. Whether irisin is in fact secreted by human skeletal muscle has been called into question recently due to a reported lack of specificity in the ELISA-based detection method used to measure irisin in several publications on this topic (Albrecht et al. 2015). This may serve to explain the inconsistencies reported in regards to circulating irisin concentrations following exercise (Catoire and Kersten, 2015). However in a recent study using tandem mass-spectroscopy as a highly sensitive and more specific method of irisin detection, aerobic interval training was shown to increase circulating concentrations of irisin by 15\% (Jedrychowski et al. 2015). As reviewed by Chen et al. (2016), irisin could mediate some of the beneficial effects of exercise by regulating the browning of white adipose tissue (Stanford et al. 2015), improving lipid and glucose metabolism, and reducing insulin resistance as well as treating related metabolic diseases in humans and mice. Irisin has also been associated with more favourable lipid profiles (Oelmann et al. 2016). In mice, irisin secreted by contracting skeletal muscle, induces the browning of white adipose tissue by upregulating the expression of uncoupling protein 1 (UCP1) and by stimulating mitochondrial biogenesis in adipose tissue (Boström et al. 2012, Liu et al. 2013), increasing overall energy expenditure as well as reducing both weight and insulin resistance (Boström et al. 2012, Højlund and Boström 2013). Future studies are necessary to identify if these effects in mice can be translated to humans. 
Very limited work has focused on the potential roles of irisin in the context of pregnancy. Placental expression of fibronectin type III domain-containing protein 5 (FNDC5), the pre-cursor of irisin, has been localized in uterine decidual tissues, in invading trophoblast cells and in the exchange region (villous trees) of the placenta across gestation (Garcés et al. 2014). Further, circulating concentrations of irisin have been measured in the serum of healthy pregnant women across pregnancy, with an increase of $16 \%$ and $21 \%$ in the second and third trimesters, respectively (Garcés et al. 2014). Of clinical importance, levels of circulating irisin measured in umbilical cord blood at the time of delivery are positively correlated with offspring birth weight (Joung et al. 2015), with the lowest irisin concentrations observed in infants demonstrating evidence of IUGR (Baka et al. 2015). Whether irisin confers any advantage to the processes involved in placental development and/or function is currently unknown. However, the associations between circulating irisin concentrations and fetal growth profiles are certainly intriguing and demand further attention. These relationships also suggest a potential role for exercise-induced irisin secretion, as part of the myokine secretome, to further improve maternal and/or feto-placental physiology in such a fashion as to optimize fetal growth in utero.

\section{Other Myokines}

There are many other myokines that have been shown to respond to skeletal muscle contractions but for which evidence is either non-existent or lacking to demonstrate a systemic increase. Therefore, it is unclear whether these myokines act locally in skeletal muscle alone, or whether they have the ability to act distally on distinct tissue beds to alter cellular function (i.e. the placenta). These myokines include: Interleukin-7 (IL-7), Interleukin-8 (IL-8), leukemia inhibitory factor (LIF), brain-derived neutrophic factor (BDNF), myostatin, decorin, myonectin, 
fibroblast growth factor 2, monocyte chemoattractant Protein-1 (MCP-1), angiopoietin-like 4 (ANGPTL-4) and secreted protein acidic and rich in cysteine (SPARC). Of these "other myokines", IL-8, LIF, and BDNF, when studied in isolation outside of the context of exercise physiology, have been found to have positive influences on processes of early placental development and/or function across pregnancy (Tapia et al. 2008, Kawamura et al. 2009, 2011, Jovanović et al. 2010, Krishnan et al. 2013, Winship et al. 2015) (Table 1). As such, further investigation into the potential roles of these myokines as mediators of optimized fetal growth observed in exercising women is strongly encouraged. Specifically, determination of whether these myokines have the ability to exert endocrine function is paramount. If these myokines are found to act in an endocrine fashion, their ability to improve maternal physiology and the development/function of the placenta suggests that they may be a set of exercise-induced factors involved in the optimization of fetal growth across gestation.

\section{Clinical Application}

Hundreds of myokines are secreted in response to exercise-induced skeletal muscle contraction. Many of these myokines have important anti-inflammatory and metabolic effects, accounting for some of the protective benefits of engaging in regular exercise. For the vast majority of myokines, their effects in the context of pregnancy, and more specifically on the development and function of the placenta - the vital organ of pregnancy - remain unknown. For the handful of myokines that have been examined in isolation for their impact on the placenta, observed effects include enhanced aspects of early placental development, including increased trophoblast migration and uterine wall invasion, and establishment of robust utero-placental and feto-placental circulations. Moreover, some of the individual chemokines/cytokines found 
in the myokine secretome are known to directly influence placental function across pregnancy, capable of regulating nutrient sensing and macronutrient delivery to the fetus. The current published literature suggests that IL-6, IL-15, FKN/CX3CL1 and irisin are elevated systemically in response to acute bouts of exercise in non-pregnant individuals. The specific intensities of exercise required to stimulate the production and secretion of these myokines in the nonpregnant population are not fully understood and for some vigorous and/or endurance-type physical activity levels may be required. For the other myokines discussed in this review, the influence of the type and intensity of exercise on the levels of these myokines in circulation in non-pregnant individuals have yet to be fully characterized. As this is a newer area of research, the effects of exercise on the production secretion of myokines in the pregnant population remains to be investigated. At this time, we do not if the current recommendations of regular bouts of 20-30 minutes of moderate physical activity during pregnancy may influence the production/secretion of myokines. Without further investigations of myokines in the context of pregnancy, the impact of maternal exercise on the myokine secretome, and the subsequent effects of myokines on the placenta and on the developing fetus cannot be discounted.

Current evidence overwhelmingly suggests that maternal exercise during pregnancy serves to optimize the uterine environment to allow for appropriate fetal growth, protecting against fetal growth extremes (SGA and LGA). We must now focus our attention on understanding the nuanced mechanisms underlying the beneficial effects of exercise on the placenta, and we speculate that the myokine secretome may hold many of the answers to this question. Through our discussion on the effects of myokines in the non-pregnant population and the effects of certain myokines in isolation on placental tissues, it is clear that myokines 
could be signalling molecules involved in regulating fetal growth via our proposed mechanisms of improved maternal physiology, enhanced placental development and improved placental macronutrient transport. Awareness of the exact mechanisms through which myokines exert their effects will provide clinicians with important mechanistic knowledge to support public health guidelines and recommendations as well as appropriately educate pregnant women about the benefits of exercise during pregnancy. Knowledge about the specific mechanisms whereby exercise alters organ function and metabolism is also required to prescribe the appropriate form of exercise as therapy (Pedersen and Saltin 2006). Although we acknowledge that historically implementing lifestyle interventions during pregnancy has been very challenging and most often women are non-compliant, there is currently a lack of guidance with respect to exercise during pregnancy and a lack of promotion of exercise in the pregnant population as a whole. A better understanding of myokine signalling in the context of pregnancy may be helpful in public health messaging by offering an additional benefit of engaging in physical activity. This knowledge would be an important motivational for physicians to promote this type of lifestyle intervention during pregnancy and to encourage women to engage in these activities during their pregnancy. Further, understanding how myokine signaling modulates placental development/function may lead to the discovery of new therapeutic targets for pregnancy-specific diseases such as IUGR, GDM and preeclampsia, and thus improve maternal and fetal health outcomes. Additionally, this knowledge may contribute to the future development of other therapeutic interventions, which while recognizing the ongoing challenges with compliance to lifestyle interventions during pregnancy, may allow all 
pregnant women to benefit from the advantageous effects of myokine secretion during pregnancy on placental development/function and on the regulation of fetal growth.

\section{Conclusion}

It is well known that regular exercise is an important part of a healthy lifestyle. Most importantly, exercise during pregnancy confers health benefits for two individuals - both the mother and her developing fetus. We propose that myokines are important exercise factors produced and secreted by skeletal muscles during pregnancy and act as signaling molecules systemically, including at the level of the placenta, to optimize fetal growth. Specifically, we have proposed three potential mechanisms through which myokines may act to optimize fetal growth trajectories; namely, improvements in maternal physiology, placental development and placenta macronutrient transport to the fetus. As maternal physical inactivity continues to prevail, understanding the mechanisms underlying the benefits of exercise during pregnancy are of utmost importance. This understanding would allow for the capitalization of the "teachable moment of pregnancy", motivating women to engage in regular physical activity to benefit themselves as well as their baby.

\section{Conflicts of Interest Statement}

There are no conflicts of interest to declare.

\section{Acknowledgements}

The following funds were used to support the authors: Faculty of Graduate and Postdoctoral Studies, University of Ottawa (C.D.); Canadian Foundation for Innovation Leaders Opportunity Fund (S.B); CIHR New Investigator Award (K.B); Canadian Institute of Health Research (CIHR) (130543 CIA - S.B); CIHR (142298 MOP- K.B, S.B); W. Garfield Weston Foundation (K.A.); Molly 
Towell Perinatal Research Foundation (S.B); Institut de Recherche l'Hôpital Montfort

(C.A); Natural Sciences and Engineering Research Council of Canada (NSERC) Discovery grant

(2015-06263 - CA); Faculty of Health Sciences, University of Ottawa (C.D., S.B.) 


\section{References}

Akerstrom, T., Steensberg, A., Keller, P., Keller, C., Penkowa, M., and Pedersen, B.K. 2005. Exercise induces interleukin-8 expression in human skeletal muscle. J. Physiol. 563(Pt 2): 507-516. doi:10.1113/jphysiol.2004.077610.

Albrecht, E., Norheim, F., Thiede, B., Holen, T., Ohashi, T., Schering, L., Lee, S., Brenmoehl, J., Thomas, S., Drevon, C.A., Erickson, H.P., and Maak, S. 2015. Irisin - a myth rather than an exercise-inducible myokine. Sci. Rep. 5: 8889. doi:10.1038/srep08889.

Artal, R., O'Toole, M., and White, S. 2003. Guidelines of the American College of Obstetricians and Gynecologists for exercise during pregnancy and the postpartum period. Br. J. Sports Med. 37(1): 6-12. doi:10.1136/bjsm.37.1.6.

Artal, R., and Sherman, C. 1999. Exercise during pregnancy: safe and beneficial for most. Phys. Sportsmed. 27(8): 51-75. doi:10.3810/psm.1999.08.947.

Baka, S., Malamitsi-Puchner, A., Boutsikou, T., Boutsikou, M., Marmarinos, A., Hassiakos, D., Gourgiotis, D., and Briana, D.D. 2015. Cord blood irisin at the extremes of fetal growth. Metabolism, 64(11): 1515-1520. doi:10.1016/j.metabol.2015.07.020.

Barakat, R., Perales, M., Garatachea, N., Ruiz, J.R., and Lucia, A. 2015. Exercise during pregnancy. A narrative review asking: what do we know? Br. J. Sports Med. 49(21): 1377-1381. doi:10.1136/bjsports-2015-094756.

Barber, E.M., and Pollard, J.W. 2003. The uterine NK cell population requires IL-15 but these cells are not required for pregnancy nor the resolution of a Listeria monocytogenes infection. J. Immunol. Baltim. Md 1950 171(1): 37-46.

Baz, B., Riveline, J.-P., and Gautier, J.-F. 2016. ENDOCRINOLOGY OF PREGNANCY: Gestational diabetes mellitus: definition, aetiological and clinical aspects. Eur. J. Endocrinol. Eur. Fed. Endocr. Soc. 174(2): R43-51. doi:10.1530/EJE-15-0378.

Bergmann, A., Zygmunt, M., and Clapp, J.F. 2004. Running throughout pregnancy: effect on placental villous vascular volume and cell proliferation. Placenta, 25(8-9): 694-698. doi:10.1016/j.placenta.2004.02.005.

Bessinger, R.C., and McMurray, R.G. 2003. Substrate utilization and hormonal responses to exercise in pregnancy. Clin. Obstet. Gynecol. 46(2): 467-478.

Borodulin, K.M., Evenson, K.R., Wen, F., Herring, A.H., and Benson, A.M. 2008. Physical Activity Patterns during Pregnancy: Med. Sci. Sports Exerc. 40(11): 1901-1908. doi:10.1249/MSS.0b013e31817f1957.

Boström, P., Wu, J., Jedrychowski, M.P., Korde, A., Ye, L., Lo, J.C., Rasbach, K.A., Boström, E.A., Choi, J.H., Long, J.Z., Kajimura, S., Zingaretti, M.C., Vind, B.F., Tu, H., Cinti, S., Højlund, K., Gygi, S.P., and Spiegelman, B.M. 2012. A PGC1- $\alpha$-dependent myokine that drives brownfat-like development of white fat and thermogenesis. Nature, 481(7382): 463-468. doi:10.1038/nature10777.

Bredin, S.S.D., Foulds, H.J.A., Burr, J.F., and Charlesworth, S.A. 2013. Risk assessment for physical activity and exercise clearance. Can. Fam. Physician, 59(5): 515-517.

Brett K.E., Ferraro, Z.M., Holcik, M., and Adamo, K.B. 2015. Prenatal physical activity and diet composition affect the expression of nutrient transporters and mTOR signaling molecules in the human placenta. Placenta, 36(2): 204-212. doi:10.1016/j.placenta.2014.11.015. 
Brett, K.E., Ferraro, Z.M., Yockell-Lelievre, J., Gruslin, A., and Adamo, K.B. 2014. Maternal-Fetal Nutrient Transport in Pregnancy Pathologies: The Role of the Placenta. Int. J. Mol. Sci. 15(9): 16153-16185. doi:10.3390/ijms150916153.

Busquets, S., Figueras, M., Almendro, V., López-Soriano, F.J., and Argilés, J.M. 2006. Interleukin15 increases glucose uptake in skeletal muscle. An antidiabetogenic effect of the cytokine. Biochim. Biophys. Acta 1760(11): 1613-1617. doi:10.1016/j.bbagen.2006.09.001.

Butte, N.F., Wong, W.W., Treuth, M.S., Ellis, K.J., and Smith, E.O. 2004. Energy requirements during pregnancy based on total energy expenditure and energy deposition. Am. J. Clin. Nutr. 79(6): 1078-1087.

Carey, A.L., Steinberg, G.R., Macaulay, S.L., Thomas, W.G., Holmes, A.G., Ramm, G., Prelovsek, O., Hohnen-Behrens, C., Watt, M.J., James, D.E., Kemp, B.E., Pedersen, B.K., and Febbraio, M.A. 2006. Interleukin-6 increases insulin-stimulated glucose disposal in humans and glucose uptake and fatty acid oxidation in vitro via AMP-activated protein kinase. Diabetes, 55(10): 2688-2697. doi:10.2337/db05-1404.

Catoire, M., and Kersten, S. 2015. The search for exercise factors in humans. FASEB J. Off. Publ. Fed. Am. Soc. Exp. Biol. 29(5): 1615-1628. doi:10.1096/fj.14-263699.

Catoire, M., Mensink, M., Kalkhoven, E., Schrauwen, P., and Kersten, S. 2014. Identification of human exercise-induced myokines using secretome analysis. Physiol. Genomics, 46(7): 256-267. doi:10.1152/physiolgenomics.00174.2013.

Charlesworth, S., Foulds, H.J.A., Burr, J.F., and Bredin, S.S.D. 2011. Evidence-based risk assessment and recommendations for physical activity clearance: pregnancy. Appl. Physiol. Nutr. Metab. Physiol. Appliquée Nutr. Métabolisme, 36 Suppl 1: S33-48. doi:10.1139/h11-061.

Chen, N., Li, Q., Liu, J., and Jia, S. 2016. Irisin, an exercise-induced myokine as a metabolic regulator: an updated narrative review. Diabetes Metab. Res. Rev. 32(1): 51-59. doi:10.1002/dmrr.2660.

Chiesa, C., Osborn, J.F., Haass, C., Natale, F., Spinelli, M., Scapillati, E., Spinelli, A., and Pacifico, L. 2008. Ghrelin, leptin, IGF-1, IGFBP-3, and insulin concentrations at birth: is there a relationship with fetal growth and neonatal anthropometry? Clin. Chem. 54(3): 550558. doi:10.1373/clinchem.2007.095299.

Cid, M., and González, M. 2016. Potential benefits of physical activity during pregnancy for the reduction of gestational diabetes prevalence and oxidative stress. Early Hum. Dev. 94: 57-62. doi:10.1016/j.earlhumdev.2016.01.007.

Clapp, J.F. 1996. Morphometric and neurodevelopmental outcome at age five years of the offspring of women who continued to exercise regularly throughout pregnancy. J. Pediatr. 129(6): 856-863.

Clapp, J.F. 2003. The effects of maternal exercise on fetal oxygenation and feto-placental growth. Eur. J. Obstet. Gynecol. Reprod. Biol. 110: S80-S85. doi:10.1016/S03012115(03)00176-3.

Clapp, J.F. and Capeless, E.L. 1991. The changing glycemic response to exercise during pregnancy. Am. J. Obstet. Gynecol. 165(6 Pt 1): 1678-1683.

Clapp, J.F., and Capeless, E.L. 1990. Neonatal morphometrics after endurance exercise during pregnancy. Am. J. Obstet. Gynecol. 163(6 Pt 1): 1805-1811. 
Clapp, J.F., Kim, H., Burciu, B., and Lopez, B. 2000a. Beginning regular exercise in early pregnancy: effect on fetoplacental growth. Am. J. Obstet. Gynecol. 183(6): 1484-1488. doi:10.1067/mob.2000.107096.

Clapp, J.F., Stepanchak, W., Tomaselli, J., Kortan, M., and Faneslow, S. 2000b. Portal vein blood flow-effects of pregnancy, gravity, and exercise. Am. J. Obstet. Gynecol. 183(1): 167172. doi:10.1067/mob.2000.105902.

Clapp J.F., Little, K.D., Appleby-Wineberg, S.K., and Widness, J.A. 1995. The effect of regular maternal exercise on erythropoietin in cord blood and amniotic fluid. Am. J. Obstet. Gynecol. 172(5): 1445-1451.

Davenport, M.H., Skow, R.J., and Steinback, C.D. 2016. Maternal Responses to Aerobic Exercise in Pregnancy. Clin. Obstet. Gynecol. doi:10.1097/GRF.0000000000000201.

Davies, G.A.L., Wolfe, L.A., Mottola, M.F., and MacKinnon, C. 2003. Joint SOGC/CSEP clinical practice guideline: exercise in pregnancy and the postpartum period. Can. J. Appl. Physiol. 28(3): 330+.

Dempsey, J.C., Butler, C.L., and Williams, M.A. 2005. No need for a pregnant pause: physical activity may reduce the occurrence of gestational diabetes mellitus and preeclampsia. Exerc. Sport Sci. Rev. 33(3): 141-149.

Duncombe, D., Wertheim, E.H., Skouteris, H., Paxton, S.J., and Kelly, L. 2009. Factors related to exercise over the course of pregnancy including women's beliefs about the safety of exercise during pregnancy. Midwifery, 25(4): 430-438. doi:10.1016/j.midw.2007.03.002.

Ellingsgaard, H., Hauselmann, I., Schuler, B., Habib, A.M., Baggio, L.L., Meier, D.T., Eppler, E., Bouzakri, K., Wueest, S., Muller, Y.D., Hansen, A.M.K., Reinecke, M., Konrad, D., Gassmann, M., Reimann, F., Halban, P.A., Gromada, J., Drucker, D.J., Gribble, F.M., Ehses, J.A., and Donath, M.Y. 2011. Interleukin-6 enhances insulin secretion by increasing glucagon-like peptide-1 secretion from $L$ cells and alpha cells. Nat. Med. 17(11): 1481-1489. doi:10.1038/nm.2513.

Febbraio, M.A., Hiscock, N., Sacchetti, M., Fischer, C.P., and Pedersen, B.K. 2004. Interleukin-6 is a novel factor mediating glucose homeostasis during skeletal muscle contraction. Diabetes, 53(7): 1643-1648.

Febbraio, M.A., and Pedersen, B.K. 2002. Muscle-derived interleukin-6: mechanisms for activation and possible biological roles. FASEB J. Off. Publ. Fed. Am. Soc. Exp. Biol. 16(11): 1335-1347. doi:10.1096/fj.01-0876rev.

Feldser, D., Agani, F., Iyer, N.V., Pak, B., Ferreira, G., and Semenza, G.L. 1999. Reciprocal positive regulation of hypoxia-inducible factor 1 alpha and insulin-like growth factor 2 . Cancer Res. 59(16): 3915-3918.

Ferraro, Z.M., Gaudet, L., and Adamo, K.B. 2012. The Potential Impact of Physical Activity During Pregnancy on Maternal and Neonatal Outcomes: Obstet. Gynecol. Surv. 67(2): 99-110. doi:10.1097/OGX.0b013e318242030e.

Ferris, L.T., Williams, J.S., and Shen, C.-L. 2007. The effect of acute exercise on serum brainderived neurotrophic factor levels and cognitive function. Med. Sci. Sports Exerc. 39(4): 728-734. doi:10.1249/mss.0b013e31802f04c7.

Fischer, C.P., Plomgaard, P., Hansen, A.K., Pilegaard, H., Saltin, B., and Pedersen, B.K. 2004. Endurance training reduces the contraction-induced interleukin- 6 mRNA expression in 
human skeletal muscle. Am. J. Physiol. Endocrinol. Metab. 287(6): E1189-1194. doi:10.1152/ajpendo.00206.2004.

Garcés, M.F., Peralta, J.J., Ruiz-Linares, C.E., Lozano, A.R., Poveda, N.E., Torres-Sierra, A.L., Eslava-Schmalbach, J.H., Alzate, J.P., Sánchez, Á.Y., Sanchez, E., Angel-Müller, E., RuízParra, A.I., Diéguez, C., Nogueiras, R., and Caminos, J.E. 2014. Irisin Levels During Pregnancy and Changes Associated With the Development of Preeclampsia. J. Clin. Endocrinol. Metab. 99(6): 2113-2119. doi:10.1210/jc.2013-4127.

Gavard, J.A., and Artal, R. 2008. Effect of exercise on pregnancy outcome. Clin. Obstet. Gynecol. 51(2): 467-480. doi:10.1097/GRF.0b013e31816feb1d.

Gold, S.M., Schulz, K.-H., Hartmann, S., Mladek, M., Lang, U.E., Hellweg, R., Reer, R., Braumann, K.-M., and Heesen, C. 2003. Basal serum levels and reactivity of nerve growth factor and brain-derived neurotrophic factor to standardized acute exercise in multiple sclerosis and controls. J. Neuroimmunol. 138(1-2): 99-105.

Görgens, S.W., Eckardt, K., Jensen, J., Drevon, C.A., and Eckel, J. 2015. Exercise and Regulation of Adipokine and Myokine Production. Prog. Mol. Biol. Transl. Sci. 135: 313-336. doi:10.1016/bs.pmbts.2015.07.002.

Gray, S.R., and Kamolrat, T. 2011. The effect of exercise induced cytokines on insulin stimulated glucose transport in C2C12 cells. Cytokine, 55(2): 221-228. doi:10.1016/j.cyto.2011.04.019.

Haggarty, P. 2010. Fatty acid supply to the human fetus. Annu. Rev. Nutr. 30: 237-255. doi:10.1146/annurev.nutr.012809.104742.

van Hall, G., Steensberg, A., Sacchetti, M., Fischer, C., Keller, C., Schjerling, P., Hiscock, N., Møller, K., Saltin, B., Febbraio, M.A., and Pedersen, B.K. 2003. Interleukin-6 stimulates lipolysis and fat oxidation in humans. J. Clin. Endocrinol. Metab. 88(7): 3005-3010. doi:10.1210/jc.2002-021687.

Hanna, J., Goldman-Wohl, D., Hamani, Y., Avraham, I., Greenfield, C., Natanson-Yaron, S., Prus, D., Cohen-Daniel, L., Arnon, T.I., Manaster, I., Gazit, R., Yutkin, V., Benharroch, D., Porgador, A., Keshet, E., Yagel, S., and Mandelboim, O. 2006. Decidual NK cells regulate key developmental processes at the human fetal-maternal interface. Nat. Med. 12(9): 1065-1074. doi:10.1038/nm1452.

Hannan, N.J., Jones, R.L., White, C.A., and Salamonsen, L.A. 2006. The chemokines, CX3CL1, CCL14, and CCL4, promote human trophoblast migration at the feto-maternal interface. Biol. Reprod. 74(5): 896-904. doi:10.1095/biolreprod.105.045518.

Hannan, N.J., and Salamonsen, L.A. 2008. CX3CL1 and CCL14 regulate extracellular matrix and adhesion molecules in the trophoblast: potential roles in human embryo implantation. Biol. Reprod. 79(1): 58-65. doi:10.1095/biolreprod.107.066480.

Harrod, C.S., Chasan-Taber, L., Reynolds, R.M., Fingerlin, T.E., Glueck, D.H., Brinton, J.T., and Dabelea, D. 2014. Physical Activity in Pregnancy and Neonatal Body Composition: The Healthy Start Study. Obstet. Gynecol. 124(2, PART 1): 257-264. doi:10.1097/AOG.0000000000000373.

Herr, F., Liang, O.D., Herrero, J., Lang, U., Preissner, K.T., Han, V.K.M., and Zygmunt, M. 2003. Possible angiogenic roles of insulin-like growth factor II and its receptors in uterine vascular adaptation to pregnancy. J. Clin. Endocrinol. Metab. 88(10): 4811-4817. doi:10.1210/jc.2003-030243. 
Højlund, K., and Boström, P. 2013. Irisin in obesity and type 2 diabetes. J. Diabetes Complications 27(4): 303-304. doi:10.1016/j.jdiacomp.2013.04.002.

Hopkins, S.A., and Cutfield, W.S. 2011. Exercise in pregnancy: weighing up the long-term impact on the next generation. Exerc. Sport Sci. Rev. 39(3): 120-127. doi:10.1097/JES.0b013e31821a5527.

Hytten, F.E., and Paintin, D.B. 1963. Increase in plasma volume during normal pregnancy. J. Obstet. Gynaecol. Br. Emp. 70: 402-407.

Jackson, M.R., Gott, P., Lye, S.J., Ritchie, J.W., and Clapp, J.F. 1995. The effects of maternal aerobic exercise on human placental development: placental volumetric composition and surface areas. Placenta, 16(2): 179-191.

Jackson, M.R., Mayhew, T.M., and Boyd, P.A. 1992. Quantitative description of the elaboration and maturation of villi from 10 weeks of gestation to term. Placenta 13(4): 357-370.

Jansson, T. and Powell, T.L. 2006. Human Placental Transport in Altered Fetal Growth: Does the Placenta Function as a Nutrient Sensor? - A Review. Placenta, 27, Supplement: 91-97. doi:10.1016/j.placenta.2005.11.010.

Jansson, T., Rosario, F.J., Gaccioli, F., Lager, S., Jones, H.N., Roos, S., Jansson, T., and Powell, T.L. 2013. Activation of Placental mTOR Signaling and Amino Acid Transporters in Obese Women Giving Birth to Large Babies. J. Clin. Endocrinol. Metab. 98(1): 105-113. doi:10.1210/jc.2012-2667.

Jansson, T., and Powell, T.L. 2000. Placental nutrient transfer and fetal growth. Nutrition, 16(78): 500-502. doi:10.1016/S0899-9007(00)00323-3.

Jansson, T., and Powell, T.L. 2013. Role of placental nutrient sensing in developmental programming. Clin. Obstet. Gynecol. 56(3): 591-601. doi:10.1097/GRF.0b013e3182993a2e.

Jedrychowski, M.P., Wrann, C.D., Paulo, J.A., Gerber, K.K., Szpyt, J., Robinson, M.M., Nair, K.S., Gygi, S.P., and Spiegelman, B.M. 2015. Detection and Quantitation of Circulating Human Irisin by Tandem Mass Spectrometry. Cell Metab. 22(4): 734-740. doi:10.1016/j.cmet.2015.08.001.

Jones, H.N., Jansson, T., and Powell, T.L. 2009. IL-6 stimulates system A amino acid transporter activity in trophoblast cells through STAT3 and increased expression of SNAT2. Am. J. Physiol. Cell Physiol. 297(5): C1228-1235. doi:10.1152/ajpcell.00195.2009.

Joung, K.E., Park, K.-H., Filippaios, A., Dincer, F., Christou, H., and Mantzoros, C.S. 2015. Cord blood irisin levels are positively correlated with birth weight in newborn infants.

Metabolism, 64(11): 1507-1514. doi:10.1016/j.metabol.2015.07.019.

Jovanović, M., Stefanoska, I., Radojcić, L., and Vićovac, L. 2010. Interleukin-8 (CXCL8) stimulates trophoblast cell migration and invasion by increasing levels of matrix metalloproteinase (MMP)2 and MMP9 and integrins alpha5 and beta1. Reprod. Camb. Engl. 139(4): 789798. doi:10.1530/REP-09-0341.

Juhl, M., Olsen, J., Andersen, P.K., Nøhr, E.A., and Andersen, A.-M.N. 2010. Physical exercise during pregnancy and fetal growth measures: a study within the Danish National Birth Cohort. Am. J. Obstet. Gynecol. 202(1): 63.e1-63.e8. doi:10.1016/j.ajog.2009.07.033.

Kawamura, K., Kawamura, N., Kumazawa, Y., Kumagai, J., Fujimoto, T., and Tanaka, T. 2011. Brain-derived neurotrophic factor/tyrosine kinase $B$ signaling regulates human 
trophoblast growth in an in vivo animal model of ectopic pregnancy. Endocrinology, 152(3): 1090-1100. doi:10.1210/en.2010-1124.

Kawamura, K., Kawamura, N., Sato, W., Fukuda, J., Kumagai, J., and Tanaka, T. 2009. Brainderived neurotrophic factor promotes implantation and subsequent placental development by stimulating trophoblast cell growth and survival. Endocrinology, 150(8): 3774-3782. doi:10.1210/en.2009-0213.

Keller, C., Steensberg, A., Hansen, A.K., Fischer, C.P., Plomgaard, P., and Pedersen, B.K. 2005. Effect of exercise, training, and glycogen availability on IL-6 receptor expression in human skeletal muscle. J. Appl. Physiol. Bethesda Md 1985 99(6): 2075-2079. doi:10.1152/japplphysiol.00590.2005.

Kelly, M., Keller, C., Avilucea, P.R., Keller, P., Luo, Z., Xiang, X., Giralt, M., Hidalgo, J., Saha, A.K., Pedersen, B.K., and Ruderman, N.B. 2004. AMPK activity is diminished in tissues of IL-6 knockout mice: the effect of exercise. Biochem. Biophys. Res. Commun. 320(2): 449454. doi:10.1016/j.bbrc.2004.05.188.

Krishnan, T., Winship, A., Sonderegger, S., Menkhorst, E., Horne, A.W., Brown, J., Zhang, J.-G., Nicola, N.A., Tong, S., and Dimitriadis, E. 2013. The role of leukemia inhibitory factor in tubal ectopic pregnancy. Placenta, 34(11): 1014-1019. doi:10.1016/j.placenta.2013.09.003.

Lager, S., Jansson, N., Olsson, A.L., Wennergren, M., Jansson, T., and Powell, T.L. 2011. Effect of IL-6 and TNF- $\alpha$ on fatty acid uptake in cultured human primary trophoblast cells. Placenta, 32(2): 121-127. doi:10.1016/j.placenta.2010.10.012.

Laplante, M., and Sabatini, D.M. 2012. mTOR signaling in growth control and disease. Cell, 149(2): 274-293. doi:10.1016/j.cell.2012.03.017.

Larqué, E., Krauss-Etschmann, S., Campoy, C., Hartl, D., Linde, J., Klingler, M., Demmelmair, H., Caño, A., Gil, A., Bondy, B., and Koletzko, B. 2006. Docosahexaenoic acid supply in pregnancy affects placental expression of fatty acid transport proteins. Am. J. Clin. Nutr. 84(4): 853-861.

Lee, Y.S., Morinaga, H., Kim, J.J., Lagakos, W., Taylor, S., Keshwani, M., Perkins, G., Dong, H., Kayali, A.G., Sweet, I.R., and Olefsky, J. 2013. The fractalkine/CX3CR1 system regulates $\beta$ cell function and insulin secretion. Cell, 153(2): 413-425. doi:10.1016/j.cell.2013.03.001. Liu, J.-J., Wong, M.D.S., Toy, W.C., Tan, C.S.H., Liu, S., Ng, X.W., Tavintharan, S., Sum, C.F., and Lim, S.C. 2013. Lower circulating irisin is associated with type 2 diabetes mellitus. J. Diabetes Complications, 27(4): 365-369. doi:10.1016/j.jdiacomp.2013.03.002.

Mandò, C., Tabano, S., Pileri, P., Colapietro, P., Marino, M.A., Avagliano, L., Doi, P., Bulfamante, G., Miozzo, M., and Cetin, I. 2013. SNAT2 expression and regulation in human growthrestricted placentas. Pediatr. Res. 74(2): 104-110. doi:10.1038/pr.2013.83.

May, L.E., Glaros, A., Yeh, H.-W., Clapp, J.F., and Gustafson, K.M. 2010. Aerobic exercise during pregnancy influences fetal cardiac autonomic control of heart rate and heart rate variability. Early Hum. Dev. 86(4): 213-217. doi:10.1016/j.earlhumdev.2010.03.002.

May, L.E., Suminski, R.R., Langaker, M.D., Yeh, H.-W., and Gustafson, K.M. 2012. Regular maternal exercise dose and fetal heart outcome. Med. Sci. Sports Exerc. 44(7): 12521258. doi:10.1249/MSS.0b013e318247b324.

Marklund, P., Mattsson, C.M., Wåhlin-Larsson, B., Ponsot, E., Lindvall, B., Lindvall, L., Ekblom, B., and Kadi, F. 2013. Extensive inflammatory cell infiltration in human skeletal muscle in 
response to an ultraendurance exercise bout in experienced athletes. J. Appl. Physiol. Bethesda Md 1985 114(1): 66-72. doi:10.1152/japplphysiol.01538.2011.

Matthews, V.B., Aström, M.-B., Chan, M.H.S., Bruce, C.R., Krabbe, K.S., Prelovsek, O., Akerström, T., Yfanti, C., Broholm, C., Mortensen, O.H., Penkowa, M., Hojman, P., Zankari, A., Watt, M.J., Bruunsgaard, H., Pedersen, B.K., and Febbraio, M.A. 2009. Brainderived neurotrophic factor is produced by skeletal muscle cells in response to contraction and enhances fat oxidation via activation of AMP-activated protein kinase. Diabetologia, 52(7): 1409-1418. doi:10.1007/s00125-009-1364-1.

Moyer, C., Livingston, J., Fang, X., and May, L.E. 2015. Influence of exercise mode on pregnancy outcomes: ENHANCED by Mom project. BMC Pregnancy Childbirth, 15: 133. doi:10.1186/s12884-015-0556-6.

Nascimento, S.L., Pudwell, J., Surita, F.G., Adamo, K.B., and Smith, G.N. 2014. The effect of physical exercise strategies on weight loss in postpartum women: a systematic review and meta-analysis. Int. J. Obes. 2005 38(5): 626-635. doi:10.1038/ijo.2013.183.

Nielsen, A.R., Mounier, R., Plomgaard, P., Mortensen, O.H., Penkowa, M., Speerschneider, T., Pilegaard, H., and Pedersen, B.K. 2007. Expression of interleukin-15 in human skeletal muscle effect of exercise and muscle fibre type composition. J. Physiol. 584(Pt 1): 305312. doi:10.1113/jphysiol.2007.139618.

Nieman, D.C., Davis, J.M., Henson, D.A., Walberg-Rankin, J., Shute, M., Dumke, C.L., Utter, A.C., Vinci, D.M., Carson, J.A., Brown, A., Lee, W.J., McAnulty, S.R., and McAnulty, L.S. 2003. Carbohydrate ingestion influences skeletal muscle cytokine mRNA and plasma cytokine levels after a 3-h run. J. Appl. Physiol. Bethesda Md 1985 94(5): 1917-1925. doi:10.1152/japplphysiol.01130.2002.

Nieman, D.C., Davis, J.M., Henson, D.A., Gross, S.J., Dumke, C.L., Utter, A.C., Vinci, D.M., Carson, J.A., Brown, A., McAnulty, S.R., McAnulty, L.S., and Triplett, N.T. 2005. Muscle cytokine mRNA changes after $2.5 \mathrm{~h}$ of cycling: influence of carbohydrate. Med. Sci. Sports Exerc. 37(8): 1283-1290.

Oelmann, S., Nauck, M., Völzke, H., Bahls, M., and Friedrich, N. 2016. Circulating Irisin Concentrations Are Associated with a Favourable Lipid Profile in the General Population. PloS One, 11(4): e0154319. doi:10.1371/journal.pone.0154319.

Oken, E., and Gillman, M.W. 2003. Fetal origins of obesity. Obes. Res. 11(4): 496-506. doi:10.1038/oby.2003.69.

O’Toole, M.L. 2003. Physiologic aspects of exercise in pregnancy. Clin. Obstet. Gynecol. 46(2): 379-389.

Owe, K.M., Nystad, W., and B $\varnothing$, K. 2009. Association between regular exercise and excessive newborn birth weight. Obstet. Gynecol. 114(4): 770-776. doi:10.1097/AOG.0b013e3181b6c105.

Pedersen. 2009. The diseasome of physical inactivity--and the role of myokines in muscle--fat cross talk. J. Physiol. 587(Pt 23): 5559-5568. doi:10.1113/jphysiol.2009.179515.

Pedersen. 2011. Muscles and their myokines. J. Exp. Biol. 214(2): 337-346. doi:10.1242/jeb.048074.

Pedersen, Akerström, T.C.A., Nielsen, A.R., and Fischer, C.P. 2007. Role of myokines in exercise and metabolism. J. Appl. Physiol. Bethesda Md 1985 103(3): 1093-1098. doi:10.1152/japplphysiol.00080.2007. 
Pedersen, B.K., and Febbraio, M.A. 2012. Muscles, exercise and obesity: skeletal muscle as a secretory organ. Nat. Rev. Endocrinol. 8(8): 457-465. doi:10.1038/nrendo.2012.49.

Pedersen, B.K., and Fischer, C.P. 2007. Beneficial health effects of exercise--the role of IL-6 as a myokine. Trends Pharmacol. Sci. 28(4): 152-156. doi:10.1016/j.tips.2007.02.002.

Pedersen, B.K. and Febbraio, M.A. 2008. Muscle as an endocrine organ: focus on musclederived interleukin-6. Physiol. Rev. 88(4): 1379-1406. doi:10.1152/physrev.90100.2007.

Pedersen, B.K. and Hoffman-Goetz, L. 2000. Exercise and the immune system: regulation, integration, and adaptation. Physiol. Rev. 80(3): 1055-1081.

Pedersen, B.K. and Saltin, B. 2006. Evidence for prescribing exercise as therapy in chronic disease. Scand. J. Med. Sci. Sports 16 Suppl 1: 3-63. doi:10.1111/j.16000838.2006.00520.x.

Petersen, A.M.W., and Pedersen, B.K. 2005. The anti-inflammatory effect of exercise. J. Appl. Physiol. Bethesda Md 1985 98(4): 1154-1162. doi:10.1152/japplphysiol.00164.2004.

Pettitt, D.J., and Jovanovic, L. 2001. Birth weight as a predictor of type 2 diabetes mellitus: the U-shaped curve. Curr. Diab. Rep. 1(1): 78-81.

Quinn, L., Anderson, Conner, Pistilli, and Wolden-Hanson. 2011. Overexpression of interleukin15 in mice promotes resistance to diet-induced obesity, increased insulin sensitivity, and markers of oxidative skeletal muscle metabolism. Int. J. Interferon Cytokine Mediat. Res.: 29. doi:10.2147/IJICMR.S19007.

Raschke, S., and Eckel, J. 2013. Adipo-Myokines: Two Sides of the Same Coin-Mediators of Inflammation and Mediators of Exercise. Mediators Inflamm. 2013: 1-16. doi:10.1155/2013/320724.

Ren, H., Zhao, T., Sun, J., Wang, X., Liu, J., Gao, S., Yu, M., and Hao, J. 2013. The CX3CL1/CX3CR1 reprograms glucose metabolism through HIF-1 pathway in pancreatic adenocarcinoma. J. Cell. Biochem. 114(11): 2603-2611. doi:10.1002/jcb.24608.

Riechman, S.E., Balasekaran, G., Roth, S.M., and Ferrell, R.E. 2004. Association of interleukin-15 protein and interleukin-15 receptor genetic variation with resistance exercise training responses. J. Appl. Physiol. Bethesda Md 1985 97(6): 2214-2219. doi:10.1152/japplphysiol.00491.2004.

Rinnov, A., Yfanti, C., Nielsen, S., Akerström, T.C.A., Peijs, L., Zankari, A., Fischer, C.P., and Pedersen, B.K. 2014. Endurance training enhances skeletal muscle interleukin-15 in human male subjects. Endocrine, 45(2): 271-278. doi:10.1007/s12020-013-9969-z.

Roos, S., Jansson, N., Palmberg, I., Säljö, K., Powell, T.L., and Jansson, T. 2007. Mammalian target of rapamycin in the human placenta regulates leucine transport and is downregulated in restricted fetal growth. J. Physiol. 582(Pt 1): 449-459. doi:10.1113/jphysiol.2007.129676.

Roos, S., Powell, T.L., and Jansson, T. 2009. Placental mTOR links maternal nutrient availability to fetal growth. Biochem. Soc. Trans. 37(Pt 1): 295-298. doi:10.1042/BST0370295.

Ryu, J., Lee, C.-W., Hong, K.-H., Shin, J.-A., Lim, S.-H., Park, C.-S., Shim, J., Nam, K.B., Choi, K.-J., Kim, Y.-H., and Han, K.H. 2008. Activation of fractalkine/CX3CR1 by vascular endothelial cells induces angiogenesis through VEGF-A/KDR and reverses hindlimb ischaemia. Cardiovasc. Res. 78(2): 333-340. doi:10.1093/cvr/cvm067.

Sibai, B.M., and Frangieh, A. 1995. Maternal adaptation to pregnancy. Curr. Opin. Obstet. Gynecol. 7(6): 420-426. 
Soultanakis, H.N., Artal, R., and Wiswell, R.A. 1996. Prolonged exercise in pregnancy: glucose homeostasis, ventilatory and cardiovascular responses. Semin. Perinatol. 20(4): 315327.

Stanford, K.I., Middelbeek, R.J.W., and Goodyear, L.J. 2015. Exercise Effects on White Adipose Tissue: Beiging and Metabolic Adaptations. Diabetes, 64(7): 2361-2368. doi:10.2337/db15-0227.

Starkie, R., Ostrowski, S.R., Jauffred, S., Febbraio, M., and Pedersen, B.K. 2003. Exercise and IL-6 infusion inhibit endotoxin-induced TNF-alpha production in humans. FASEB J. Off. Publ. Fed. Am. Soc. Exp. Biol. 17(8): 884-886. doi:10.1096/fj.02-0670fje.

Steensberg, A., Fischer, C.P., Keller, C., Møller, K., and Pedersen, B.K. 2003. IL-6 enhances plasma IL-1ra, IL-10, and cortisol in humans. Am. J. Physiol. Endocrinol. Metab. 285(2): E433-437. doi:10.1152/ajpendo.00074.2003.

Steensberg, A., van Hall, G., Osada, T., Sacchetti, M., Saltin, B., and Klarlund Pedersen, B. 2000. Production of interleukin- 6 in contracting human skeletal muscles can account for the exercise-induced increase in plasma interleukin-6. J. Physiol. 529 Pt 1: 237-242.

Suzuki, K., Nakaji, S., Yamada, M., Totsuka, M., Sato, K., and Sugawara, K. 2002. Systemic inflammatory response to exhaustive exercise. Cytokine kinetics. Exerc. Immunol. Rev. 8: 6-48.

Szukiewicz, D., Kochanowski, J., Pyzlak, M., Szewczyk, G., Stangret, A., and Mittal, T.K. 2013. Fractalkine (CX3CL1) and Its Receptor CX3CR1 May Contribute to Increased Angiogenesis in Diabetic Placenta. Mediators Inflamm. 2013: e437576. doi:10.1155/2013/437576, $10.1155 / 2013 / 437576$.

Tamura, Y., Watanabe, K., Kantani, T., Hayashi, J., Ishida, N., and Kaneki, M. 2011. Upregulation of circulating IL-15 by treadmill running in healthy individuals: is IL-15 an endocrine mediator of the beneficial effects of endurance exercise? Endocr. J. 58(3): 211-215.

Tapia, A., Salamonsen, L.A., Manuelpillai, U., and Dimitriadis, E. 2008. Leukemia inhibitory factor promotes human first trimester extravillous trophoblast adhesion to extracellular matrix and secretion of tissue inhibitor of metalloproteinases-1 and -2. Hum. Reprod. Oxf. Engl. 23(8): 1724-1732. doi:10.1093/humrep/den121.

The American College of Obstetricians and Gynecologists. 2015. ACOG Committee Opinion No. 650: Physical Activity and Exercise During Pregnancy and the Postpartum Period. Obstet. Gynecol. 126(6): e135-142. doi:10.1097/AOG.0000000000001214.

Whitaker, R.C. 2004. Predicting preschooler obesity at birth: the role of maternal obesity in early pregnancy. Pediatrics, 114(1): e29-36.

Winship, A., Correia, J., Zhang, J.-G., Nicola, N.A., and Dimitriadis, E. 2015. Leukemia Inhibitory Factor (LIF) Inhibition during Mid-Gestation Impairs Trophoblast Invasion and Spiral Artery Remodelling during Pregnancy in Mice. PloS One, 10(10): e0129110. doi:10.1371/journal.pone.0129110.

Wolfe, L., and Mottola, M. 2002. Physical activity readiness medical examination for pregnancy (PARmed-X for pregnancy). Available from http://www.csep.ca/cmfiles/publications/parq/parmed-xpreg.pdf [accessed 14 June 2016]. 
Yeo, N.H., Woo, J., Shin, K.O., Park, J.Y., and Kang, S. 2012. The effects of different exercise intensity on myokine and angiogenesis factors. J. Sports Med. Phys. Fitness 52(4): 448454.

Zinker, B.A., Britz, K., and Brooks, G.A. 1990. Effects of a 36-hour fast on human endurance and substrate utilization. J. Appl. Physiol. Bethesda Md 1985 69(5): 1849-1855.

Zygmunt, M., Hahn, D., Kiesenbauer, N., Münstedt, K., and Lang, U. 1998. Invasion of cytotrophoblastic (JEG-3) cells is up-regulated by interleukin-15 in vitro. Am. J. Reprod. Immunol. N. Y. N 1989 40(5): 326-331.

Zygmunt, M., Herr, F., Keller-Schoenwetter, S., Kunzi-Rapp, K., Münstedt, K., Rao, C.V., Lang, U., and Preissner, K.T. 2002. Characterization of human chorionic gonadotropin as a novel angiogenic factor. J. Clin. Endocrinol. Metab. 87(11): 5290-5296. doi:10.1210/jc.2002020642. 
Table 1. Other exercise-induced myokines that may play a role in optimizing fetal growth

\begin{tabular}{|c|c|c|c|c|}
\hline Myokine & Response to Exercise & $\begin{array}{l}\text { Potential Effects on } \\
\text { Maternal Physiology }\end{array}$ & $\begin{array}{c}\text { Potential Effects on } \\
\text { Placental Development }\end{array}$ & $\begin{array}{c}\text { Potential Effects on } \\
\text { Placental Function }\end{array}$ \\
\hline \multirow[t]{2}{*}{ IL-8 } & $\begin{array}{l}\text {-Skeletal muscle concentrations increase } \\
\text { in response to strenuous exercise } \\
\text { (Nieman et al. 2001, 2003, 2005, } \\
\text { Marklund et al. 2013) }\end{array}$ & $\begin{array}{l}\text {-Chemoattracts and } \\
\text { degranulates neutrophils } \\
\text { to mediate inflammation } \\
\text { (Pedersen et al. 2007) }\end{array}$ & \multirow{2}{*}{$\begin{array}{l}\text {-Promotes trophoblast } \\
\text { cell migration (Hanna et } \\
\text { al. 2006), viability, } \\
\text { proliferation and } \\
\text { invasion (Jovanović et } \\
\text { al. 2010) }\end{array}$} & $\begin{array}{l}\text {-Direct effects of IL-8 } \\
\text { on placental function } \\
\text { unknown }\end{array}$ \\
\hline & $\begin{array}{l}\text {-Small and transient net release } \\
\text { following exercise that does not } \\
\text { contribute to an increase in circulating } \\
\text { plasma levels (Akerstrom et al. 2005) }\end{array}$ & $\begin{array}{l}\text {-Stimulates angiogenesis } \\
\text { (Pedersen et al. 2007) }\end{array}$ & & $\begin{array}{l}\text {-Stimulates skeletal } \\
\text { muscle glucose } \\
\text { transport via AMPK } \\
\text { phosphorylation } \\
\text { during exercise (Gray } \\
\text { and Kamolrat 2011) }\end{array}$ \\
\hline \multirow[t]{2}{*}{ LIF } & $\begin{array}{l}\text {-Skeletal muscle mRNA expression is } \\
\text { elevated following acute bouts of } \\
\text { exercise (Broholm et al. 2008) and heavy } \\
\text { resistance exercise (Broholm et al. 2011) }\end{array}$ & $\begin{array}{l}\text {-Mediates inflammation } \\
\text { (Chodorowska et al. 2004) }\end{array}$ & \multirow{2}{*}{$\begin{array}{l}\text { - Facilitates trophoblast } \\
\text { adhesion to uterine } \\
\text { endometrial cells and } \\
\text { regulates invasion of } \\
\text { the uterine wall to } \\
\text { allow for spiral artery } \\
\text { remodeling (Tapia et al. } \\
\text { 2008, Winship et al. } \\
\text { 2015) }\end{array}$} & \multirow[t]{2}{*}{$\begin{array}{l}\text {-Direct effects of LIF } \\
\text { on placental function } \\
\text { unknown }\end{array}$} \\
\hline & $\begin{array}{l}\text { Skeletal muscle protein levels and } \\
\text { circulating levels are unchanged in } \\
\text { response to acute exercise (Broholm et } \\
\text { al. 2008) }\end{array}$ & $\begin{array}{l}\text {-Promotes the growth and } \\
\text { differentiation of various } \\
\text { types of target cells } \\
\text { (Chodorowska et al. 2004) }\end{array}$ & & \\
\hline \multirow[t]{2}{*}{ BDNF } & $\begin{array}{l}\text {-Skeletal muscle mRNA and protein } \\
\text { expression are increased by acute } \\
\text { endurance exercise (Matthews et al. } \\
\text { 2009) }\end{array}$ & \multirow[t]{2}{*}{$\begin{array}{l}\text {-Enhances lipid oxidation } \\
\text { in via the activation of } \\
\text { AMPK (Matthews et al. } \\
\text { 2009) }\end{array}$} & \multirow{2}{*}{$\begin{array}{l}\text {-Both In vitro model in } \\
\text { vivo paracrine signalling } \\
\text { by the BDNF/TrkB } \\
\text { system is important for } \\
\text { placenta trophoblast } \\
\text { growth and survival } \\
\text { (Kawamura et al. 2009, } \\
\text { 2011) }\end{array}$} & \multirow[t]{2}{*}{$\begin{array}{l}\text {-Direct effects of } \\
\text { BDNF on placental } \\
\text { function unknown }\end{array}$} \\
\hline & $\begin{array}{l}\text {-Exercise-induced increases in circulating } \\
\text { levels of BDNF attributed to production } \\
\text { by the brain (Gold et al. 2003, Ferris et al. } \\
2007 \text {, Matthews et al. 2009) }\end{array}$ & & & \\
\hline
\end{tabular}

